\title{
Phylogenetic analysis and intrageneric structure of the genus Hyphomicrobium and the related genus Filomicrobium
}

\author{
Frederick A. Rainey, ${ }^{1}$ Naomi Ward-Rainey, ${ }^{1}$ Christian G. Gliesche ${ }^{2}$ \\ and Erko Stackebrandt ${ }^{1}$
}

\author{
Author for correspondence: Erko Stackebrandt. Tel: +495312616 352. Fax: +49532 2616418 \\ e-mail: erko@gbf-de
}

\footnotetext{
1 Deutsche Sammlung von Mikroorganismen und Zellkulturen $\mathrm{GmbH}$, D38124 Braunschweig, Germany

2 Institut für Allgemeine Mikrobiologie, Universität Kiel, Am Botanischen Garten 1-9, D-24118 Kiel, Germany
}

\begin{abstract}
Almost complete 165 rDNA sequences from the type strains of seven species of the genus Hyphomicrobium and of Filomicrobium fusiforme have been determined. The Hyphomicrobium species form two phylogenetic clusters that are only moderately related to each other. While cluster I contains the type species Hyphomicrobium vulgare, Hyphomicrobium aestuarii, Hyphomicrobium hollandicum and Hyphomicrobium zavarzinii, cluster II comprises Hyphomicrobium facilis, Hyphomicrobium denitrificans and Hyphomicrobium methylovorum. Within the two species clusters, the species are highly related. Phylogenetically, Filomicrobium fusiforme clusters moderately with Hyphomicrobium species. The lack of distinguishing phenotypical properties presently excludes the possibility of describing cluster II as a new genus.
\end{abstract}

Keywords: Hyphomicrobium, Filomicrobium, intrageneric structure

\section{INTRODUCTION}

Hyphomicrobia are appendaged bacteria that reproduce by budding and have a dimorphic life cycle involving non-motile prosthecate mother cells and motile swarmer cells (Hirsch, 1989). In contrast to morphologically similar taxa such as Hyphomonas (Moore \& Weiner, 1989), Pedomicrobium (Gebers, 1989), Dichotomicrobium (Hirsch \& Hoffmann, 1989), Filomicrobium (Schlesner, 1987) or Rhodomicrobium (Imhoff \& Trüper, 1989), hyphomicrobia are restricted facultative methylotrophs capable of growth on reduced $\mathrm{C}_{1}$ compounds such as methanol, methylated amines or formate (Harder \& Attwood, 1978). In recent years, hyphomicrobia became of special interest because of their versatility and ability to use toxic waste compounds that are not metabolized by other methylotrophs (Hanson, 1992). They can be used in the denitrification of sewage (Nyberg et al., 1992) or drinking water (Liessnes, 1993) or in the bioremediation of $\mathrm{C}_{1}$ compounds such as halomethanes, methyl sulphates and methylated phosphates (Large \& Bamforth, 1988) and, consequently, many strains have

This paper is dedicated to Dr Peter Hirsch on the occasion of his 70th birthday.

The EMBL accession numbers for the sequences reported in this paper are Y14302-Y14313. been isolated and included in these and in taxonomic studies (Gebers et al., 1986; Gliesche et al., 1988; Stackebrandt et al., 1988; Roggentin \& Hirsch, 1989; Holm et al., 1996).

The genus Hyphomicrobium presently contains nine species (Hirsch, 1989; Urakami et al., 1995), one of which, $H$. coagulans (Takada, 1975), is not available from any culture collection, while $H$. indicum has been discussed in the literature to be a non-authentic member of the genus (Hirsch, 1989; Urakami et al., 1995). Of the other species, only a few strains have been included in chemotaxonomic studies (Guckert et al., 1991; Sittig \& Hirsch, 1992) and in the phylogenetic analysis of 16S rRNA (Stackebrandt et al., 1988; Roggentin \& Hirsch, 1989; Tsuji et al., 1990) and 5S RNA sequences (Stackebrandt et al., 1988; Boulygina et al., 1993). These studies have indicated that the genus belongs to the alpha subclass of the class Proteobacteria. However, according to the results of DNA dot-blot hybridization studies on hundreds of Hyphomicrobium strains (Holm et al., 1996), 19 DNA similarity clusters were identified, which points towards the presence of a significantly higher number of species than presently described.

In this study, we present a phylogenetic analysis on all available type strains of the genus Hyphomicrobium, which will allow subsequent affiliation of environ- 
Table 1. Bacterial strains analysed in this study

\begin{tabular}{|c|c|c|}
\hline Strain* & Other designation(s)* & Reference/source \\
\hline H. aestuarii IFAM NQ-521 $\mathrm{gr}^{\mathrm{T}}$ & ATCC 27488 & Hirsch (1989) \\
\hline H. denitrificans DSM $1869^{\mathrm{T}}$ & TK 0415 = IFAM HA-905 & Urakami et al. (1995) \\
\hline H. facilis subsp. facilis IFAM H-526 ${ }^{\mathrm{T}}$ & DSM 1565, ATCC 27485 & Hirsch (1989) \\
\hline H. facilis IFAM B-522 & & Hirsch (1989) \\
\hline H. facilis subsp. tolerans IFAM I-551 ${ }^{\mathrm{T}}$ & ATCC 27489 & Hirsch (1989) \\
\hline H. facilis subsp. ureaphilum IFAM CO-582 & ATCC 27492 & Hirsch (1989) \\
\hline H. hollandicum IFAM KB-677 & ATCC 27498 & Hirsch (1989) \\
\hline H. methylovorum DSM $5458^{\mathrm{T}}$ & ATCC $35216, \mathrm{KM}-146$ & Hirsch (1989) \\
\hline H. vulgare IFAM MC-750 & ATCC 27500 & Hirsch (1989) \\
\hline H. zavarzinii IFAM ZV-622 ${ }^{\mathrm{T}}$ & ATCC 27496 & Hirsch (1989) \\
\hline H. zavarzinii IFAM ZV-580 & & Hirsch (1989) \\
\hline F. fusiforme DSM $5304^{\mathrm{T}}$ & & Schlesner (1987) \\
\hline
\end{tabular}

*ATCC, American Type Culture Collection, Rockville, MD, USA; DSM, DSMZ-Deutsche Sammlung von Mikroorganismen und Zellkulturen, Germany; IFAM, Institut für Allgemeine Mikrobiologie, University of Kiel, Germany.

mental isolates to known species and the recognition of novel genomic nuclei that may represent novel species.

\section{METHODS}

Bacterial strains. Strains analysed in this study are listed in Table 1. Growth media and culture conditions followed described procedures for the cultivation of Hyphomicrobium strains (DSM catalogue of strains, 1993, 1996).

16S rDNA sequence determination and analysis. Extraction of genomic DNA, PCR-mediated amplification of the 16S rDNA and sequence analysis of the purified PCR products were performed as described previously (Rainey et al., 1996), and the sequence reactions were electrophoresed using a model 373A automatic DNA sequencer (Applied Biosystems).

To determine the closest relatives of strains of hyphomicrobia, their phylogenetic position was determined initially using the database ARB (Strunk \& Ludwig, 1995). A fine resolution of the relatedness between hyphomicrobia and their closest relatives was perfomed using the ae 2 editor (Maidak et al., 1994). Phylogenetic dendrograms were reconstructed using treeing algorithms contained in the PHYLIP package (Felsenstein, 1993). Bootstrap values were determined using the PHYLIP package (Felsenstein, 1993).

Nucleotide sequence accession numbers. The accession numbers of the $16 \mathrm{~S}$ rDNAs of references strains were: Agrobacterium tumefaciens, X67223; Methylobacterium organophilum, M29028; Methylobacterium extorquens, M29027; Phyllobacterium myrsinacearum, D12789; Mesorhizobium loti, D12791; Rhodobium marinum, D30790; Rhodobium orientis, D30792; and Rhodomicrobium vannielii, M34127.

\section{RESULTS}

The almost complete primary structure of the $16 \mathrm{~S}$ rDNA of eight type strains of Hyphomicrobium species and of Filomicrobium fusiforme as well as of four additional strains of Hyphomicrobium were sequenced. Their EMBL accession numbers are: Hyphomicrobium vulgare IFAM MC-750 ${ }^{\mathrm{T}}$ (Y14302), Hyphomicrobium hollandicum IFAM KB-677 ${ }^{\mathrm{T}}$ (Y14303), Hyphomicrobium aestuarii IFAM NQ-521 $\mathrm{gr}^{\mathrm{T}}$ (Y14304), Hyphomicrobium zavarzinii IFAM ZV-622 ${ }^{\mathrm{T}}$ (Y14305), Hyphomicrobium zavarzinii IFAM ZV-580 (Y14306), Hyphomicrobium methylovorum DSM $5458^{\mathrm{T}}$ (Y14307), Hyphomicrobium denitrificans DSM $1869^{\mathrm{T}}$ (Y14308), Hyphomicrobium facilis subsp. facilis IFAM H-526 ${ }^{\mathrm{T}}$ (Y14309), Hyphomicrobium facilis subsp. ureaphilum IFAM CO-582 $2^{\mathrm{T}}$ (Y14310), Hyphomicrobium facilis subsp. tolerans IFAM I-551 microbium facilis IFAM B-522 (Y14312) and Filomicrobium fusiforme DSM 5304 ${ }^{\mathrm{T}}$ (Y14313).

The length of sequences ranged between 1410 and 1446 bases, which corresponded to 91 and $94 \%$ of the Escherichia coli sequence (Brosius et al., 1978), respectively. The position of the type strain of the type species of Hyphomicrobium was searched for in the ARB database (Strunk \& Ludwig, 1995), and the position within the 'Rhodomicrobium vannielii assemblage' (Maidak et al., 1994) could be confirmed. Subsequent phylogenetic analysis was carried out using the ae 2 editor. The sequences of Hyphomicrobium strains and of Filomicrobium fusiforme were aligned with each other and with representatives of neighbouring taxa. A total of 1360 nucleotides were used in the analysis, and phylogenetic trees were generated using the algorithms of De Soete (1983) and those included in the PHYLIP package (Felsenstein, 1993). All trees showed very similar topologies, in that all hyphomicrobia as well as $F$. fusiforme formed a phylogenetically coherent group, which was most closely related to Rhodomicrobium vannielii (around $90 \% 16$ S rDNA sequence similarity), while the other reference organisms were more distantly related (between 87 and $89.5 \%$ similarity). The only differences in 


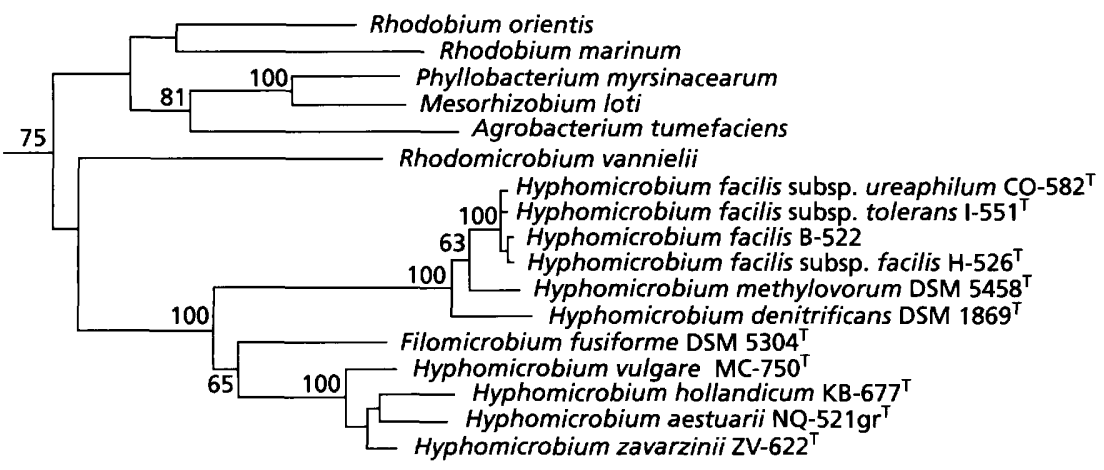

$5 \%$
Fig. 1. Dendrogram showing the phylogenetic position of the genera Hyphomicrobium and Filomicrobium among members of the alpha-2 subclass of the class Proteobacteria. The tree was constructed by the neighbour-joining method (Saitou \& Nei, 1987), using corrected distance values (Jukes \& Cantor, 1969). The sequences of Methylobacterium extorquens and Methylobacterium organophilum were used to root the dendrogram. The position of $H$. zavarzinii ZV-580 corresponds fully to that of strain $Z \mathrm{~V}-622^{\top}$. Bootstrap values (expressed as percentages of 500 replications) of $65 \%$ or more are indicated at the branch points. Bar, $5 \%$ sequence divergence. the tree topologies were observed in the branching point of Filomicrobium fusiforme.

The type strains of the seven Hyphomicrobium species formed two 16S rDNA clusters in which the species showed a high degree of relatedness (Fig. 1). Bootstrap values of $100 \%$ indicated that these clusters are of statistical significance. Cluster I contained the type species of the genus $H$. vulgare, as well as $H$. hollandicum, $H$. aestuarii and $H$. zavarzinii. The $16 \mathrm{~S}$ rDNA sequence similarities ranged between 97.8 and $98 \cdot 8 \%$. Strains ZV-622 ${ }^{\mathrm{T}}$ and ZV-580 had identical $16 \mathrm{~S}$ rDNA sequences. Cluster II contained the species $H$. methylovorum, $H$. denitrificans and $H$. facilis and its two subspecies $H$. facilis subsp. tolerans IFAM I-551 ${ }^{\mathrm{T}}$ and $H$. facilis subsp. ureaphilum IFAM CO-582 ${ }^{\mathrm{T}}$. The last three strains, as well as strain IFAM B-522, shared $99.9 \%$ sequence similarity. The sequence similarities of the type strains of the three species ranged from $97 \cdot 3$ to $98.8 \%$. Members of clusters I and II were separated by $6.4-8.0 \%$ sequence differences. The two clusters can be differentiated clearly by a set of cluster-specific nucleotides, which can be considered a molecular signature. The positions of these nucleotides in the $16 \mathrm{~S}$ rDNA sequence are indicated in Table 2.

The branching point of the $F$. fusiforme sequence was close to the bifurcation point of the two Hyphomicrobium lineages. Although in the algorithm of De Soete (1983) this species grouped with members of cluster II, it branched with members of cluster I in the neighbour-joining analysis (Saitou \& Nei, 1987). The finding that $16 \mathrm{~S}$ rDNA similarity values for $F$. fusiforme were about $2 \%$ higher for members of cluster I than for members of cluster II may be indicative of a specific relatedness to the former cluster as indicated in Fig. 1. This relationship is also expressed in the presence of 13 signature nucleotides that are shared between $F$. fusiforme and members of cluster I, while nine signatures are common to $F$. fusiforme and members of cluster II. Bootstrap values of the branching points $(65 \%$ significance for cluster I members compared with $23 \%$ significance for cluster II members) are too low to make a decision about the phylogenetic neighbour of $F$. fusiforme. The primary
Table 2. 16S rDNA signature nucleotides that define clusters I and II of Hyphomicrobium species and their occurrence in the $16 \mathrm{~S}$ rDNA sequence of $F$. fusiforme

\begin{tabular}{|lccc|}
\hline Position* & Cluster I & Cluster II & F. fusiforme \\
\hline 99 & A & G & G \\
$131-231$ & U-A & C-G & C-G \\
$137-226$ & U-A & C-G & U-A \\
$138-225$ & A-U & U-A & A-U \\
$139-224$ & U-A & A-U & U.U \\
$140-223$ & C-G & U-A & U-A \\
$141-222$ & G-C & A-U & G-C \\
$144-178$ & A-C & A-U & A-U \\
$153-168$ & C-G & C-A & C-G \\
$154-167$ & U-G & C-G & U.U \\
Loop $187-190$ & UUCG & GA[A/G]A & GAGA \\
$240-286$ & C-G & A-U & C-G \\
$295-302$ & C-G & U-A & C-G \\
$241-285$ & U-A & G-C & G-C \\
$418-425$ & U-A & C-G & C-G \\
422 & C & A & A \\
$501-544$ & C-G & U-A & C-G \\
$661-744$ & G-C & A-U & A-U \\
$670-736$ & A-U & G-C & A-U \\
818 & U & G & G \\
849 & G & U & G \\
$1007-1022$ & U-U & C-G & G \\
$1008-1021$ & U.U & C-G & U.U \\
$1254-1283$ & G-U & C-G & U-U \\
$1264-1271$ & C-G & U-A & G-C \\
1304 & G & A & G \\
$1310-1327$ & G-C & A-U & G-C \\
\hline
\end{tabular}

${ }^{a}$ E. coli position (Brosius et al., 1978).

structure of the 16S rDNA of $F$. fusiforme, unlike those of Hyphomicrobium species, lack a stretch between positions 1257 and 1277 . This position is also missing in Rhodobium marinum, while it is present in its closest relative Rhodobium orientis and in the sequence of the other reference organisms of the alpha-2 subclass included in Fig. 1. 


\section{DISCUSSION}

The membership of Hyphomicrobium species in the alpha-2 subclass of the class Proteobacteria confirms earlier findings that were based on the analysis of $5 \mathrm{~S}$ rDNA (Stackebrandt et al., 1988; Nikitin et al., 1990) and 16S rRNA (Stackebrandt et al., 1988; Tsuji et al., 1990), determination of 16S rRNA cistron similarities (Moore, 1977; Roggentin \& Hirsch, 1989) and membrane fatty acids (Gluckert et al., 1991; Sittig \& Hirsch, 1992), but not more than five species were included in a single study. The coherency of the genus was supported by phage typing (Gliesche et al., 1988), analysis of low-molecular-mass RNA patterns (Höfle, 1990) and 16S rDNA cistron similarity studies (Roggentin \& Hirsch, 1989), while 16S rRNA cataloguing showed Filomicrobium to branch within the radiation of Hyphomicrobium (Stackebrandt et al., 1988). The intragenetic structure was elucidated by the latter two approaches, which clearly showed the phylogenetically separate position of $H$. vulgare, $H$. aestuarii and $H$. zavarzinii on the one side and $H$. facilis on the other. $H$. hollandicum and $F$. fusiforme grouped intermediate to these clusters in the studies on RNA cistron similarities (Roggentin \& Hirsch, 1989) and 16S rRNA cataloguing (Stackebrandt et al., 1988), respectively.

The distinctness of Hyphomicrobium species is demonstrated by differences of more than $1.2 \%$ in $16 \mathrm{~S} \mathrm{rDNA}$ sequence found for the most closely related species. These data confirm results of DNA-DNA hybridization studies (Moore \& Hirsch, 1972; Gebers et al., 1986) in which the separate species status was demonstrated for $H$. vulgare, $H$. aestuarii, $H$. zavarzinii and $H$. facilis. The three subspecies of $H$. facilis, showing almost identical 16S rDNA sequences, showed more than $85 \%$ DNA similarities as determined by hybridization, and these data confirm their membership of the same species. The molecular percentage $\mathrm{G}+\mathrm{C}$ content of DNA has also been used to separate members of $H$. vulgare $(61.4 \mathrm{~mol} \%), H$. facilis $(60 \mathrm{~mol} \%)$ and the pair $H$. aestuarii and $H$. zavarzinii (63-64 mol\% each) (Gebers et al., 1986), and the presence of species-specific low-molecular-mass RNA patterns was demonstrated for each of the five species studied (Höfle, 1990).

The question arises as to whether the two phylogenetically distinct clusters of Hyphomicrobium species respresent two genera or whether a single genus, including Filomicrobium fusiforme, should be maintained. The degree of $16 \mathrm{~S}$ rDNA sequence divergence between clusters I and II is as large as those found separating members of Agrobacterium, Phyllobacterium and Mesorhizobium (Fig. 1). The dissection of the genus Hyphomicrobium has been indicated before on molecular grounds (Stackebrandt et al., 1988; Roggentin \& Hirsch, 1989), but the lack of phenotypic properties specific for the newly emerging groups has postponed this step. The branching point of the Filomicrobium fusiforme line of descent should not be taken as an argument for either decision, as it is deep in any phylogenetic tree generated, and none of them is supported with high statistical significance. Also, Sittig \& Hirsch (1992), while clearly separating members of Hyphomicrobium and F. filiformis by the results of phospholipid and fatty acids analysis, could not identify specific patterns for the Hyphomicrobium species and, of all the morphological and physiological properties compiled by Hirsch (1989), only the formation of rosettes or cell clumping would identify members of cluster I, because these properties are absent in members of cluster II. The lack of nonmolecular evidence stops us from proposing a new genus for the cluster II organisms. In addition, a comprehensive taxonomic revision of the genus Hyphomicrobium should await a molecular analysis of undescribed strains for which species status has been discussed on the basis of phenotypic analysis (Vedenina et al., 1990; Sittig \& Hirsch, 1992), DNA dot-blot hybridization studies (Holm et al., 1996) and morphology (Holm et al., 1996).

\section{ACKNOWLEDGEMENTS}

We wish to thank Orsola Päuker for her help in the molecular work.

\section{REFERENCES}

Boulygina, E. S., Chumakov, K. M. \& Netrusov, A. I. (1993). Systematics of Gram-negative methylotrophic bacteria based on $5 \mathrm{~S}$ rRNA sequences. In Microbial Growth on $C_{1}$ Compounds, pp. 275-284. Edited by J. C. Murrel \& D. P. Kelly. Andover: Intercept.

Brosius, J., Palmer, M. L., Kennedy, P. J. \& Noller, H. F. (1978). Complete nucleotide sequence of the 16S ribosomal RNA gene from Escherichia coli. Proc Natl Acad Sci USA 75, 4801-4805.

De Soete, G. (1983). A least squares algorithm for fitting additive trees to proximity data. Psychometrika 48, 621-626.

Felsenstein, J. (1993). PHYLIP (phylogenetic inference package) version 3.5.1. Department of Genetics, University of Washington, Seattle.

Gebers, R. (1989). Genus Pedomicrobium Aristovskaya 1961, $957^{\mathrm{AL}}$ emend. Gebers 1981, 313, In Bergey's Manual of Systematic Bacteriology, vol. 3, 9th edn, pp. 1910-1914. Edited by J. T. Staley, M. P. Bryant, N. Pfennig \& J. G. Holt. Baltimore: Williams \& Wilkins.

Gebers, R., Martens, B., Wehmeyer, U. \& Hirsch, P. (1986). Deoxyribonucleic acid homologies of Hyphomicrobium spp., Hyphomonas spp., and other hyphal, budding bacteria. Int $J$ Syst Bacteriol 36, 241-245.

Gliesche, C. G., Holm, N. C., Beese, M., Neumann, N., Völker, H., Gebers, R. \& Hirsch, P. (1988). New bacteriophages active on strains of Hyphomicrobium. J Gen Microbiol 134, 1339-1353.

Guckert, J. B., Ringelberg, D. B., White, D., Hanson, D. S. \& Bratina, B. J. (1991). Membrane fatty acids as phenotypic markers in the polyphasic taxonomy of methylotrophs within the Proteobacteria. J Gen Microbiol 137, 2631-2641.

Hanson, R. S. (1992). Introduction. In Methane and Methanol Utilizers, pp. 1-21. Edited by J. C. Murrell \& H. Dalton. New York: Plenum Press. 
Harder, W. \& Attwood, M. M. (1978). Biology, physiology and biochemistry of hyphomicrobia. Adv Microb Physiol 17, 303-359.

Hirsch, P. (1989). Genus Hyphomicrobium Stutzer and Hartleb $1898,7^{\mathrm{AL}}$. In Bergey's Manual of Systematic Bacteriology, 9th edn, vol. 3, pp. 1897-1904. Edited by J. T. Staley, M. P. Bryant, N. Pfennig \& J. G. Holt. Baltimore: Williams \& Wilkins.

Hirsch, P. \& Hoffmann, B. (1989). Dichotomicrobium thermohalophilum, gen. nov., spec. nov., budding prosthecate bacteria from the Solar Lake (Sinai) and some related strains. Syst Appl Microbiol 11, 291-301.

Hofle, M. G. (1990). Transfer RNAs as genotypic fingerprints of eubacteria. Arch Microbiol 153, 299-304.

Holm, N. C., Gliesche, C. G. \& Hirsch, P. (1996). Diversity and structure of Hyphomicrobium populations in a sewage treatment plant and its adjacent receiving lake. Appl Environ Microbiol 62, 522-528.

Imhoff, J. F. \& Truper, H. G. (1989). Genus Rhodomicrobium Duchow and Douglas 1949, $415^{\mathrm{AL}}$. In Bergey's Manual of Systematic Bacteriology, vol. 3, 9th edn, pp. 1677-1678. Edited by J. T. Staley, M. P. Bryant, N. Pfennig \& J. G. Holt. Baltimore: Williams \& Wilkins.

Jukes, T. H. \& Cantor, C. R. (1969). Evolution of protein molecules. In Mammalian Protein Metabolism, pp. 21-132. Edited by H. N. Munro. New York: Academic Press.

Large, P. J. \& Bamforth, C. W. (1988). Methylotrophy and Biotechnology. New York: Longman Scientific \& Technical and Wiley.

Liessens, J. (1993). Removing nitrate with a methylotrophic fluidized bed: microbiological quality. J Am Water Assoc 85, 155-161.

Maidak, B. L., Larsen, N., McCaughey, M. J., Overbeek, R., Olsen, G. J., Fogel, K., Blandy, J. \& Woese, C. R. (1994). The Ribosomal Database Project. Nucleic Acids Res 22, 3485-3487.

Moore, R. L. (1977). Ribosomal ribonucleic acid cistron homologies among Hyphomicrobium and various other bacteria. Can $J$ Microbiol 23, 478-481.

Moore, R. L. \& Hirsch, P. (1972). Deoxyribonucleic acid base sequence homologies of some budding and prosthecate bacteria. $J$ Bacteriol 110, 256-261.

Moore, R. L. \& Weiner, R. M. (1989). Genus Hyphomonas (ex Pongratz 1957) Moore, Weiner and Gebers 1984, $71^{\text {vp }}$. In Bergey's Manual of Systematic Bacteriology, vol. 3, 9th edn, pp. 1904-1910. Edited by J. T. Staley, M. P. Bryant, N. Pfennig \& J. G. Holt. Baltimore: Williams \& Wilkins.

Nikitin, D. I., Yu, O., Vishnewetskaya, K., Chumakov, M. \& Zlatkin, I. V. (1990). Evolutionary relationship of some stalked and budding bacteria (genera Caulobacter, Hyphobacter,
Hyphomonas, and Hyphomicrobium) as studied by the new integral taxonomical method. Arch Microbiol 153, 123-128.

Nyberg, U., Aspegren, H., Andersson, B., Jansen, J. laC. \& Villadsen, I. S. (1992). Full-scale application of nitrogen removal with methanol as carbon source. Water Sci Technol 26, 1077-1086.

Rainey, F. A., Ward-Rainey, N., Kroppenstedt, R. M. \& Stackebrandt, E. (1996). The genus Nocardiopsis represents a phylogenetically coherent taxon and a distinct actinomycete lineage: proposal of Nocardiopsaceae fam. nov. Int $J$ Syst Bacteriol 46, 1088-1092.

Roggentin, T. \& Hirsch, P. (1989). Ribosomal RNA cistron similarities among Hyphomicrobium species and several other hyphal, budding bacteria. Syst Appl Microbiol 11, 140-147.

Saitou, N. \& Nei, M. (1987). The neighbor-joining method: a new method for reconstructing phylogenetic trees. Mol Biol Evol 4, 406-425.

Schlesner, H. (1987). Filomicrobium fusiforme gen. nov., sp. nov., a slender budding, hyphal bacterium from brackish water. Syst Appl Microbiol 10, 63-67.

Sittig, M. \& Hirsch, P. (1992). Chemotaxonomic investigation of budding and/or hyphal bacteria. Syst Appl Microbiol 15, 209-222.

Stackebrandt, E. R. G., Fischer, A., Roggentin, T., Wehmeyer, U. \& Smida, J. (1988). A phylogenetic survey of budding, and/or prosthecate, non-phototrophic eubacteria: membership of Hyphomicrobium, Hyphomonas, Pedomicrobium, Filomicrobium, Caulobacter and 'Dichotomicrobium' to the alphasubdivision of purple non-sulfur bacteria. Arch Microbiol 149, $547-556$.

Strunk, O. \& Ludwig, W. (1995). ARB - a Software Environment for Sequence Data. Munich: Department of Microbiology, Technical University of Munich.

Takada, N. (1975). A new species of Hyphomicrobium. In Proceedings of the International Symposium on Microbial Growth on $C_{1}$ Compounds, pp. 29-33. Edited by G Terui. Tokyo: Society for Fermentation Technology.

Tsuji, K., Tsien, H. C., Hanson, R. S., De Palma, S. R., Scholtz, R. \& Laroche, S. (1990). 16S ribosomal RNA sequence analysis for determination of phylogenetic relationship among methylotrophs. J Gen Microbiol 136, 1-10.

Urakami, T., Sasaki, J., Suzuki, K.-I. \& Komagata, K. (1995). Characterization and description of Hyphomicrobium denitrificans sp. nov. Int J Syst Bacteriol 45, 528-532.

Vedenina, J. Ya., N., Chernykh, A., Lebedinskii, A. V. \& Andreev, L. V. (1990). Correlations of characteristics in subgroups of the genus Hyphomicrobium. Mikrobiologiya 59, 895-902 (English translation 617-622). 